\title{
Development and optimization of antioxidant polyherbal cream using artificial neural network aided response surface methodology
}

\author{
Margaret O. Ilomuanya ${ }^{1 *}$, Chukwuebuka P. Onwubuya ${ }^{1}$, Andrew N. Amenaghawon ${ }^{2}$ \\ ${ }^{1}$ Department of Pharmaceutics and Pharmaceutical Technology, Faculty of Pharmacy, University of Lagos, Lagos, Nigeria \\ ${ }^{2}$ Department of Chemical Engineering, Faculty of Engineering, University of Benin, Benin City, Edo State, Nigeria
}

\begin{tabular}{|c|c|}
\hline \multicolumn{2}{|c|}{ ARTICLE INFO } \\
\hline \multicolumn{2}{|c|}{ Article history: } \\
\hline Received & $20 \mathrm{Jul} 2020$ \\
\hline Revised & 30 Sep 2020 \\
\hline Accepted & 28 Nov 2020 \\
\hline Online & 03 Dec 2020 \\
\hline Published & - \\
\hline \multicolumn{2}{|l|}{ Keywords: } \\
\hline \multicolumn{2}{|c|}{ Antioxidant } \\
\hline \multicolumn{2}{|c|}{ Artificial neural network } \\
\hline \multicolumn{2}{|c|}{ Formulation optimization } \\
\hline \multicolumn{2}{|c|}{ Polyherbal cream } \\
\hline \multicolumn{2}{|c|}{ Response surface methodology } \\
\hline \multicolumn{2}{|c|}{$\begin{array}{l}\text { *Corresponding author: } \\
\text { milomuanya@unilag.edu.ng }\end{array}$} \\
\hline
\end{tabular}

\begin{abstract}
A B S T R A C T
Artificial Neural Networks have become phenomenal in drug modeling, predicting experimental outcomes, and optimization studies during product development. This research investigates artificial neural networks (ANN) to optimize a novel formulation of Polyherbal face cream composed of Cymbopogon citratus, Hibiscus sabdariffa, and Ocimum gratissimum extracts. The central composite design was used to develop a framework for the products to be studied, describing the independent variables as the oil phase concentration and the emulsifying agents used in the formulation. The dependent variables/responses are viscosity, spreadability index, and particle size of the cream. The obtained responses were then optimized using ANN models. The validity of the statistical models used for predicting the observed responses was confirmed by carrying out three experimental confirmation runs at the identified optimum conditions. The viscosity of the cream formulation decreased with an increase in the amount of oil phase. However, there was a strong correlation between the amount of emulsifying phase in the emulsifier product and the viscosity or the cream. The particle sizes did not vary greatly between the various formulations regardless of the concentration of plant extract. Formulation of Polyherbal face cream composed of Cymbopogon citratus, Hibiscus sabdariffa, and Ocimum gratissimum extracts was shown to have significant antioxidant activity. A prediction of an optimized formulation was made using ANN modeling, and it was shown to have comparable results with the predicted values.
\end{abstract}

This is an open-access article licensed under the Creative Commons Attribution 4.0 International License (CC-BY). $(\propto))$ EY

\section{INTRODUCTION}

The use of artificial neural network models to derive response surface plot has found increasing use in optimization modeling. They are of great use for data sets that do not possess linear relationships. Ilomuanya et al. used a central composite design to optimize formulations of hydrogels that had wound healing properties due to infused extracts of Tetracarpidium conophorum [1]. Plant extracts have been known to contain antioxidants, which are beneficial to skin health. Antioxidants are among the most significant substances to help protect and often correct skin damage from free radicals. Free radicals are the very elements that age, destroy, and damage our skin. These harmful elements attack our skin, causing wrinkles, age spots, and deterioration of collagen. Edeoga et al. showed that they contain tannins, flavonoids, with traces of other terpenoid compounds on the evaluation of the aqueous extract of the leaves of Ocimum gratissimum [2]. Akinmoladun et al. [3] further confirmed the phytochemical constituent and antioxidant activity of extract from the leaves of Ocimum gratissimum. Chiu et al. demonstrated that the aqueous extract of basil has antioxidant activities which beneficial effects of Ocimum gratissimum aqueous extract on rats with (Carbon tetrachloride) $\mathrm{CCl}_{4}$-induced acute liver injury [4]. The antioxidant and cytoprotective activity of Ocimum gratissimum extracts against hydrogen peroxideinduced toxicity in human $\mathrm{HepG}_{2}$ cells of the liver has also been established [4]. The inhibitory effect of aqueous extracts of two varieties (red and white) of Hibiscus sabdariffa (Roselle) calyces on carbohydrate hydrolyzing enzymes ( $\alpha$-amylase and $\alpha$-glucosidase) have been evaluated to determine a possible mechanism for their anti-diabetes properties. The antidiabetic property of Roselle was a direct result of its antioxidant properties [5]. Cymbopogon citratus (lemongrass) is a potent antimicrobial and antioxidant, natural bioproduct widely used in food preservation as an alternative to synthetic compounds [6]. Oxygenated monoterpenoids are the major constituents of Cymbopogon citratus. The antimicrobial activity of the essential oil of Cymbopogon citratus against different Gram-positive and Gram-negative pathogenic bacteria, yeasts, and filamentous fungi has been evaluated by Carmo et al. [6]

Commercially available topical product formulations with medicinal properties that contain natural products in various 
proportions are not optimized. There is the variability of treatment outcomes comparing brands composed of similar herbal extracts and composition. This study targets the development of a novel and optimized formulation of face creams containing extracts from Roselle (Hibiscus sabdariffa), Lemon grass (Cymbopogon citratus), and Basil (Ocimum gratissimum) leaf extracts utilizing artificial neural networks.

\section{MATERIALS AND METHODS}

\subsection{Materials}

Benzyl alcohol (Long-Range Europe Ltd., Bedfordshire, UK), Rose Oil (Shubham Natural Products Fragrance and Exports, Uttar Pradesh, India), Cetostearyl alcohol (Ampluschem Co. Ltd., Bangkok, Thailand), Cetyl Palmitate (Strahl and Pitsch LLC, NY, USA), and Liquid Paraffin (Sigma Aldrich, St Louis Missouri, USA), Refined Palm Olein (Raffles oil LFTZ Enterprise Lagos), Tween 80 and Span 60 (obtained from Sigma Aldrich, St Louis Missouri, USA) was used for this research. All other chemicals and reagents used were of analytical grade.

\subsection{Methods}

\subsubsection{Preparation of the extract}

Leaves of Lemongrass (Cymbopogon citratus) were freshly harvested from Odogbolu Local Government Area; latitude: 6 49' 59.99" N, longitude: $3^{\circ} 45^{\prime}$ 59.99" E (Ogun State, Nigeria). Sweet Basil (Ocimum gratissimum) was freshly harvested late in the evening from a farm in Ojo Local Govt. Area; latitude: $6.4581^{\circ} \mathrm{N}, 3.2020^{\circ} \mathrm{E}$ (Lagos State, Nigeria). The dried calyces of Red Roselle (Hibiscus sabdariffa) were purchased from the local Market at Ikorodu (Lagos State, Nigeria). These herbs were identified at the Department of Botany, University of Lagos, Lagos, Nigeria. Voucher specimens assigned reference numbers LUH 7954, LUH 7955, and LUH 7956, respectively, were deposited in the institutional herbarium of the University of Lagos for reference.

One $\mathrm{kg}$ each of leaves of Lemongrass (Cymbopogon citratus); leaves of Sweet Basil (Ocimum gratissimum) and dried calyces of Red Roselle (Hibiscus sabdariffa) collected and washed in running water. The plant materials were sun- dried for seven days before milling into powder with a clean Pellet-type Hammer mill (Model MKHM500 C Opa-Locka, FL 33054). Then $500 \mathrm{~g}$ of the dried powder from each plant was macerated in $1000 \mathrm{~mL}$ of distilled water for $24 \mathrm{~h}$ at room temperature to obtain the aqueous extracts and then was lyophilized to obtain a dry solid residue using the method of Ademiluyi and Oboh [5]. The freeze-dried extract was then stored in amber glass bottles in a desiccator at $4^{\circ} \mathrm{C}$.

\subsubsection{Formulation of polyherbal creams}

The oil phase of liquid paraffin or palm oil $\left(\mathrm{X}_{1}\right)$, Tween 80/Span 60 combinations $\left(\mathrm{X}_{2}\right)$, Cetostearyl alcohol, and cetyl palmitate were melted together in a water bath (Table 1), heated to $75^{\circ} \mathrm{C}$. The aqueous phase was prepared by dissolving $0.25 \% \mathrm{w} / \mathrm{w}$ of the dried plant extracts in about $20 \%$ of the required volume of deionized water for the cream formulation at about $40^{\circ} \mathrm{C}$. Benzyl alcohol $1.5 \% \mathrm{w} / \mathrm{w}$ was then added to the aqueous mixture. The resulting mixture was then placed on a water bath, and more deionized water was added to it, up $50 \%$ of the final volume. Both phases were mixed at $70^{\circ} \mathrm{C}$ and homogenized using a portable hand blender, Kenwood Triblade System Immersion Blender HB711M 700W (Kenwood Corp.Hachioji, Tokyo) at $85 \mathrm{rpm}$ for 15 minutes. This process was replicated for different cream batches after varying the concentrations of Tween 80 / Span $60\left(\mathrm{X}_{2}\right)$ and the Oil Phase $\left(\mathrm{X}_{1}\right)$ see Table 2.

Table 1. Coded and actual values for oil and emulsifying phases of cream formulations

\begin{tabular}{lcccccc}
\hline $\begin{array}{l}\text { Independent } \\
\text { Variables (\%) }\end{array}$ & Sym. & \multicolumn{6}{c}{ Coded and Actual Levels (\% w/w) } \\
\cline { 3 - 7 } & $\mathbf{- 1 . 4 1 4}$ & $\mathbf{- 1}$ & $\mathbf{0}$ & $\mathbf{1}$ & $\mathbf{1 . 4 1 4}$ \\
\hline $\begin{array}{l}\text { Oil Phase } \\
\text { Liquid paraffin }\end{array}$ & $\mathrm{X}_{1}$ & 25 & 26.5 & 30 & 33.5 & 35 \\
$\begin{array}{l}\text { Palm oil } \\
\text { Emulsifier Phase }\end{array}$ & $\mathrm{X}_{2}$ & 7 & 7.6 & 9 & 10.4 & 11 \\
$\begin{array}{l}\text { Tween } 80 \\
\text { Span } 60\end{array}$ & & & & & & \\
\hline
\end{tabular}

The ratio of emulsifier amounts to be used for the cream formulation to produce a stable cream was determined after having considered the HLB values of the oil phase components. The Tween 80:Span 60 ratio was calculated as: 0.5923:0.4077 (for Liquid Paraffin Based Cream); and 0.4534:0.5466 (for the Palm Oil Based Cream). Rose oil

Table 2. Physicochemical characteristics of the formulations in response to variation in the oil phase and emulsifying phase (all values are reported as $\pm S D, n=3)$

\begin{tabular}{lcccccccc}
\hline Run & $\begin{array}{c}\text { Factor 1 } \\
\text { Oil Phase } \\
(\mathbf{\%} \text { w/v) }\end{array}$ & $\begin{array}{c}\text { Factor 2 } \\
\text { Emulsifier } \\
\text { Phase (\%) }\end{array}$ & $\begin{array}{c}\text { Response 1 } \\
\text { Viscosity } \\
\text { (centipoise) }\end{array}$ & $\begin{array}{c}\text { Response 2 } \\
\text { Spreadability } \\
\text { average \% change } \\
\text { in diameter) }\end{array}$ & $\begin{array}{c}\text { Response 3 } \\
\text { Particle Size } \\
(\boldsymbol{\mu m})\end{array}$ & pH & $\begin{array}{c}\text { pH } \\
\text { (after 28 days) }\end{array}$ & $\begin{array}{c}\text { Sensitivity } \\
\text { (Draize test) }\end{array}$ \\
\hline $\mathbf{S 1}$ & 26.5 & 7.6 & 5668.1 & 44.19 & 0.120 & $5.06 \pm 0.03$ & $5.05 \pm 0.02$ & NR \\
\hline $\mathbf{S 2}$ & 33.5 & 7.6 & 4362.2 & 28.78 & 0.114 & $4.76 \pm 0.08$ & $4.77 \pm 0.09$ & $\mathrm{NR}$ \\
\hline $\mathbf{S 3}$ & 25.0 & 9.0 & 5368.0 & 27.09 & 0.113 & $5.00 \pm 0.01$ & $5.00 \pm 0.01$ & $\mathrm{NR}$ \\
\hline $\mathbf{S 4}$ & 30.0 & 9.0 & 6480.0 & 40.30 & 0.140 & $4.66 \pm 0.13$ & $4.65 \pm 0.16$ & $\mathrm{NR}$ \\
\hline $\mathbf{S 5}$ & 30.0 & 9.0 & 8020.0 & 32.77 & 0.150 & $5.74 \pm 0.02$ & $5.75 \pm 0.01$ & $\mathrm{NR}$ \\
\hline $\mathbf{S 6}$ & 33.5 & 10.4 & 6002.0 & 33.57 & 0.104 & $4.65 \pm 0.16$ & $4.62 \pm 0.19$ & $\mathrm{NR}$ \\
\hline $\mathbf{S 7}$ & 30.0 & 9.0 & 8290.2 & 40.73 & 0.166 & $5.48 \pm 0.01$ & $5.49 \pm 0.05$ & $\mathrm{NR}$ \\
\hline $\mathbf{S 8}$ & 35.0 & 9.0 & 7924.1 & 49.83 & 0.085 & $4.60 \pm 0.25$ & $4.60 \pm 0.18$ & $\mathrm{NR}$ \\
\hline $\mathbf{S 9}$ & 30.0 & 7.0 & 5936.5 & 34.15 & 0.171 & $4.91 \pm 0.01$ & $4.91 \pm 0.21$ & $\mathrm{NR}$ \\
\hline $\mathbf{S 1 0}$ & 26.5 & 10.4 & 9014.3 & 34.03 & 0.144 & $5.01 \pm 0.02$ & $5.00 \pm 0.01$ & $\mathrm{NR}$ \\
\hline $\mathbf{S 1 1}$ & 30.0 & 11.0 & 8068.0 & 38.09 & 0.106 & $4.70 \pm 0.10$ & $4.69 \pm 0.11$ & $\mathrm{NR}$ \\
\hline
\end{tabular}


$(0.1 \% \mathrm{v} / \mathrm{v})$ utilized as the perfume in the formulation was added into the cream, and the resulting formulation was thoroughly mixed to obtain a homogenous mix.

\subsubsection{Experiment design}

A two-factor Central Composite Design (CCD) was used to develop the experimental design to study the response pattern and determine the optimum combination of variables to maximize the chosen responses. The independent variables investigated were the oil phase and emulsifying phase concentrations. The responses or dependent variables investigated were viscosity, spreadability, and particle size. The experimental design was developed using the data in Table 1 with Design Expert ${ }^{\circledR}$ software version 7.0.0 (Statease, Inc. Minneapolis, USA). The values of the independent variables were calculated using Equation 1 [5].

$$
x_{i}=\frac{X_{i}-X_{0}}{\Delta X_{i}}
$$

Where $x_{i}$ and $X_{i}$ are the coded and actual values of the independent variable, respectively. $X_{o}$ is the actual value of the independent variable at the center point, and $\Delta X_{i}$ is the step-change in $X_{i}$.

\subsubsection{Artificial neural network modeling}

Multilayer Full Feed Forward (MFFF) and a Multilayer Normal Feed Forward (MNFF) were evaluated to determine which was more suitable. For the training algorithm, several options were considered, and they include Incremental Back Propagation (IBP), Batch Back Propagation (BBP), Quick Propagation (QP), Generic Algorithm (GA), and LevenbergMarquadt (LM) Algorithm. For each of these learning algorithms, $70 \%$ of the experimental data was used for training the network, $15 \%$ was used for validating the model, and the remaining $15 \%$ was then used for testing the network. Validation of the data predicted by the ANN model was done by using the trained network to generate output responses for the last $15 \%$ of input data without knowledge of their actual responses, and the generated responses were then compared with their actual responses [7].

To evaluate the predictive capability of the ANN models, and to determine the efficiency of the modeling tool, the predicted responses of each model were compared with experimental responses. The predictive capability of each model was assessed using the coefficient of determination ( $\mathrm{R}^{2}$ value), root mean square error (RMSE), absolute average deviation (AAD), and mean absolute deviation (MAD) as shown in Equations 2 to 5 [7,8].

$$
\begin{gathered}
R^{2}=1-\sum_{i=1}^{n}\left[\frac{\left(y_{\text {exp }}-y_{\text {pred }}\right)^{2}}{\left(y_{\text {exp }}-y_{\text {exp }, \text { ave }}\right)^{2}}\right] \\
R M S E=\left[\frac{1}{n} \sum_{i=1}^{n}\left(y_{\text {pred }}-y_{\text {exp }}\right)^{2}\right]^{1 / 2} \\
A A D(\%)=\left[\frac{1}{n} \sum_{i=1}^{n}\left(\frac{y_{\text {exp }}-y_{\text {pred }}}{y_{\text {exp }}}\right)\right] \times 100 \\
M A D=\left[\frac{1}{n} \sum_{i=1}^{n}\left(y_{\text {pred }}-y_{\text {exp }}\right)^{2}\right]^{1 / 2}
\end{gathered}
$$

where,

$\mathrm{n}$ is the number of points

$\mathrm{y}_{\text {pred }}$ is the predicted value obtained from the model

$\mathrm{y}_{\exp }$ is the actual value

$\mathrm{y}_{\text {exp,ave }}$ is the average of the actual values.

The coefficient of determination $\left(\mathrm{R}^{2}\right)$ indicates the degree of fit for the model [8]. The closer the $\mathrm{R}^{2}$ value is to 1 , the better the model fits the actual data. $\mathrm{R}^{2}$ is a measure of the reduction in the response variability by using the repressor variables in the model, while RMSE and AAD are direct methods for describing deviations. The RMSE, AAD, and MAD between predicted and experimental values must be as small as possible [8].

\subsubsection{Physical evaluation/organoleptic characteristics}

All prepared formulations were observed for homogeneity and phase separation by visual appearance and touch. The appearance of the cream was judged by its color, opalescence, roughness, and other organoleptic properties were observed $[9,10]$. The Draize test was used to evaluate skin sensibility. (Ethical approval Protocol Number CMUL/ HREC/10/18/454). The creams were evaluated for their creaming index using Equation 6.

$$
\% C I=\frac{C C}{C T} \times 100
$$

where $\mathrm{CC}$ is the total height of the cream layer (showing phase separation), and CT is the total height of the emulsion layer (without phase separation) [9]. The creams were evaluated for spreadability, $\mathrm{pH}$, particle size, and viscosity $[9,10]$. Utilizing the method of Fahimi et al., the creams were tested on Day 1 and 30 days after preparation for microbial growth in tryptone soy agar plates [9].

\subsubsection{Evaluation of the antioxidant activity}

The free radical scavenging activity of all the extracts was evaluated by 1,1-diphenyl-2-picryl-hydrazyl (DPPH) according to the previously reported method by Shen et al. [11]. The capability of scavenging the DPPH (\% inhibition) radical was calculated by using Equation 7.

$$
\text { DPPH scavenging effect }=\frac{\left(A_{0}-A_{1}\right)}{A_{0}} \times 100
$$

where, $\mathrm{A}_{0}$ is the absorbance of the control reaction (Methanol), and $A_{1}$ is the absorbance in the presence of all the formulations or for that of the reference. All the tests were performed in triplicates.

\subsubsection{Statistical analysis}

The experimental design was developed using the data in Table 1 with Design Expert ${ }^{\circledR}$ software version 7.0.0 (Statease, Inc. Minneapolis, USA). The data were expressed as mean \pm SEM and analyzed by one-way ANOVA, followed by Dunnett's test. The data were considered statistically significant at $\mathrm{p}<0.05$.

\section{RESULTS}

\subsection{Physical Evaluation/Organoleptic Characteristics}

All the formulations had a cosmetically appealing appearance and smooth texture, and they were all homogenous with no signs of phase separation. All products 
had a pseudoplastic behavior (as shear increased, the viscosity of formulation decreases), with the particle size of the globules ranging from 0.2 to $0.4 \mu \mathrm{m}$. The particle sizes did not vary markedly for the various formulations. Thus, given varying concentrations of the oil phase and emulsifying phase, the particle sizes of the creams are comparable. The $\mathrm{pH}$ of the cream was evaluated immediately (i.e., $24 \mathrm{~h}$ post-production) and after storage for three weeks. The $\mathrm{pH}$ values were found to be relatively constant, with little variation in their values after three weeks (Table 2).

\subsection{Evaluation of Creaming Indices}

The various formulations of the cream on observation at $24 \mathrm{~h}$, seven days, and 15 days after formulation were found to exhibit creaming of various levels (Figure 1). However, Samples S1 and S3 were found to have the highest creaming index. These corresponded to formulations with the lowest amounts of oil phase $(26.5 \%$ and $25 \%$, respectively). It also showed that as the oil phase reduced, there were more significant changes in creaming and cream stability after seven days and 15 days. This effect was most marked for formulations with lower amounts of emulsifier and oil phase (S1) and evident in formulation with low emulsifier alone (S9), which showed better stability (creaming) due to the higher amount of oil phase present. The formulation containing the lowest emulsifier and oil phase (S3) showed the highest creaming (Table 2).

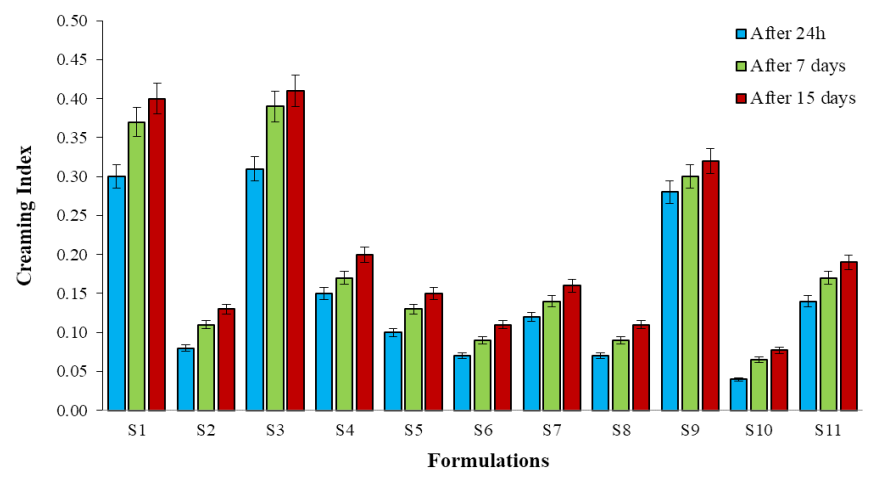

Figure 1. Evaluation of creaming index of the polyherbal cream formulations $(n=3)$

\subsection{Microbial Limit Test}

The creams were microbiologically tested using tryptone soy agar on day 1 and day 30 . On observation of the prepared plates after incubation for $48 \mathrm{~h}$, it was discovered that there was no growth of bacteria on the prepared plates. On repeating the tests after 15 days, all the samples except $\mathrm{S} 2$ were found to have no growth on the plates.

\subsection{Evaluation of the Antioxidant Activity}

The absorbance of the various extracts was obtained using a UV-VIS Spectrophotometer (Mettler Toledo AVI 195-1100nm). $800 \mu \mathrm{g} / \mathrm{mL}$ of the extract had a DPPH radical scavenging activity of $71.23 \%$ against control $\%$ inhibition of reference 98.01\%, as shown in Figure 2.
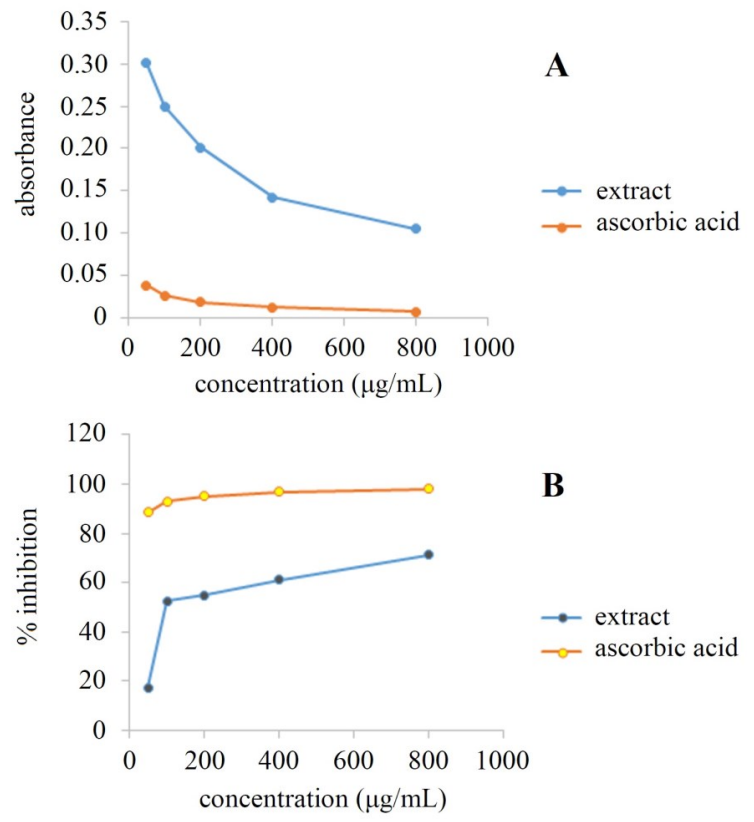

Figure 2. Plot of absorbance of extracts and ascorbic acid at various concentrations (A) and evaluation of DPPH radical scavenging activity of extract $(B)(n=3)$

\subsection{Modeling and Analysis Using ANN}

\subsubsection{Validation of ANN model results}

The values of viscosity, spreadability, and particle size predicted by the optimum ANN model are presented in Table 3 alongside the experimental values for comparison. There was reasonable agreement between the model predictions and the experimental values. The comparison of the experimental values of the response and those predicted by the ANN model showed that there was an acceptable level

Table 3. Comparison of experimental results with ANN predicted results

\begin{tabular}{|c|c|c|c|c|c|c|c|c|}
\hline \multirow{3}{*}{ Run } & \multirow{2}{*}{\multicolumn{2}{|c|}{ Input Factors }} & \multicolumn{6}{|c|}{ Responses } \\
\hline & & & \multicolumn{2}{|c|}{ Viscosity (cP) } & \multicolumn{2}{|c|}{ Spreadability (\%) } & \multicolumn{2}{|c|}{ Particle size $(\mu \mathrm{m})$} \\
\hline & $\mathbf{X}_{1}$ & $\mathbf{X}_{2}$ & Experiment & ANN & Experiment & ANN & Experiment & ANN \\
\hline S1 & 30.0 & 9.0 & 6480 & 6997 & 40.30 & 39.93 & 0.14 & 0.15 \\
\hline $\mathbf{S 2}$ & 30.0 & 7.0 & 5936 & 5936 & 34.15 & 34.15 & 0.17 & 0.17 \\
\hline $\mathbf{S 3}$ & 33.5 & 7.6 & 4362 & 4362 & 28.78 & 28.78 & 0.12 & 0.12 \\
\hline S4 & 26.5 & 7.6 & 5668 & 5668 & 44.19 & 44.19 & 0.12 & 0.12 \\
\hline$\overline{\mathrm{S5}}$ & 35.0 & 9.0 & 7924 & 7924 & 49.83 & 49.83 & 0.09 & 0.09 \\
\hline S6 & 25.0 & 9.0 & 5368 & 5368 & 27.09 & 27.09 & 0.11 & 0.11 \\
\hline $\mathbf{S 7}$ & 30.0 & 9.0 & 8020 & 6997 & 38.77 & 39.93 & 0.15 & 0.15 \\
\hline $\mathbf{S 8}$ & 33.5 & 10.4 & 6002 & 6002 & 33.57 & 33.57 & 0.11 & 0.11 \\
\hline S9 & 30.0 & 9.0 & 6490 & 6997 & 40.73 & 39.93 & 0.17 & 0.15 \\
\hline S10 & 30.0 & 11.0 & 6568 & 6568 & 38.09 & 38.09 & 0.11 & 0.11 \\
\hline S11 & 26.5 & 10.4 & 8014 & 8014 & 34.03 & 34.03 & 0.14 & 0.14 \\
\hline
\end{tabular}


of fit between the experimental and model-predicted results. The goodness of fit of the ANN models for viscosity, spreadability, and particle size are shown in Table 4. A good fit was obtained between the model prediction and the experimental observations. This claim is supported by the high $\mathrm{R}^{2}$ and adjusted $\mathrm{R}^{2}$ values. Beyond that, the error terms (RMSE, AAD, and MAD) were relatively small compared to the mean of the observations $[1,7]$.

Table 4. The goodness of fit statistics for ANN models

\begin{tabular}{lccc}
\hline Parameter & \multicolumn{3}{c}{ Response } \\
\cline { 2 - 4 } & $\begin{array}{c}\text { Viscosity } \\
(\mathbf{c P})\end{array}$ & $\begin{array}{c}\text { Spreadability } \\
\mathbf{( \% )}\end{array}$ & $\begin{array}{c}\text { Particle size } \\
(\boldsymbol{\mu} \mathbf{m})\end{array}$ \\
\hline $\mathrm{R}^{2}$ & 0.8850 & 0.9949 & 0.9304 \\
$\mathrm{R}^{2}$ Adj & 0.7700 & 0.9898 & 0.8608 \\
Mean & 6439 & 37.2300 & 0.1300 \\
RMSE & 396.98 & 0.4732 & 0.0055 \\
AAD & 0.0259 & 0.0053 & 0.0196 \\
MAD & 884 & 5.1872 & 0.02182 \\
\hline
\end{tabular}

\subsubsection{Optimization of input factors and responses}

The results of optimization carried out using genetic algorithm (GA), particle swarm optimization (PSO), and rotation inherit optimization (RIO) are summarized in Table 5. From the results, there was virtually no difference between the values obtained from the three optimization methods. The optimal values of viscosity, spreadability, and particle size obtained from the genetic algorithm were $8355.86 \mathrm{cP}$, $47.01 \%$, and $0.12 \mu \mathrm{m}$. These were obtained with oil and emulsifying phase levels of $27.86 \%$ and $11 \%$ (Table 6).

Table 5. Summary of optimization results

\begin{tabular}{lccc}
\hline Variable & GA & PSO & RIO \\
\hline Oil phase (\%) & 27.86 & 27.86 & 27.87 \\
Emulsifying phase (\%) & 11.00 & 11.00 & 11.00 \\
Maximum viscosity (cP) & 8355.86 & 8355.91 & 8355.87 \\
Maximum spreadability (\%) & 47.01 & 46.98 & 47.02 \\
Maximum particle size ( $\mu \mathrm{mm})$ & 0.12 & 0.12 & 0.12 \\
\hline
\end{tabular}

Table 6. Comparison of predicted and actual optimized results

\begin{tabular}{lcc}
\hline Results & $\begin{array}{c}\text { Predicted } \\
\text { Optimized Values }\end{array}$ & $\begin{array}{c}\text { Observed } \\
\text { Optimized Values }\end{array}$ \\
\hline Viscosity (cP) & 8355.86 & 8312.67 \\
Spreadability (\%) & 47.01 & 46.24 \\
Particle Size ( $\boldsymbol{\mu m})$ & 0.12 & 0.117 \\
\hline
\end{tabular}

The response surface plots presented in Figure $\mathbf{3 A}$ to Figure 3D show the relationship between the responses (viscosity, spreadability, and particle size) and the input factors (oil phase and emulsifying phase). Utilizing the architecture of the optimal ANN for predicting viscosity, spreadability, and particle size viscosity was found to increase with an increase in the level of the emulsifying phase, as shown in Figure 3A. The reverse was observed to the oil phase level as the viscosity was observed to decrease when the oil phase was increased. High levels of emulsifying phase combined with low oil phase levels were found to yield high viscosity values. Spreadability decreased with an increase in the emulsifying phase, as shown in Figure 3B.
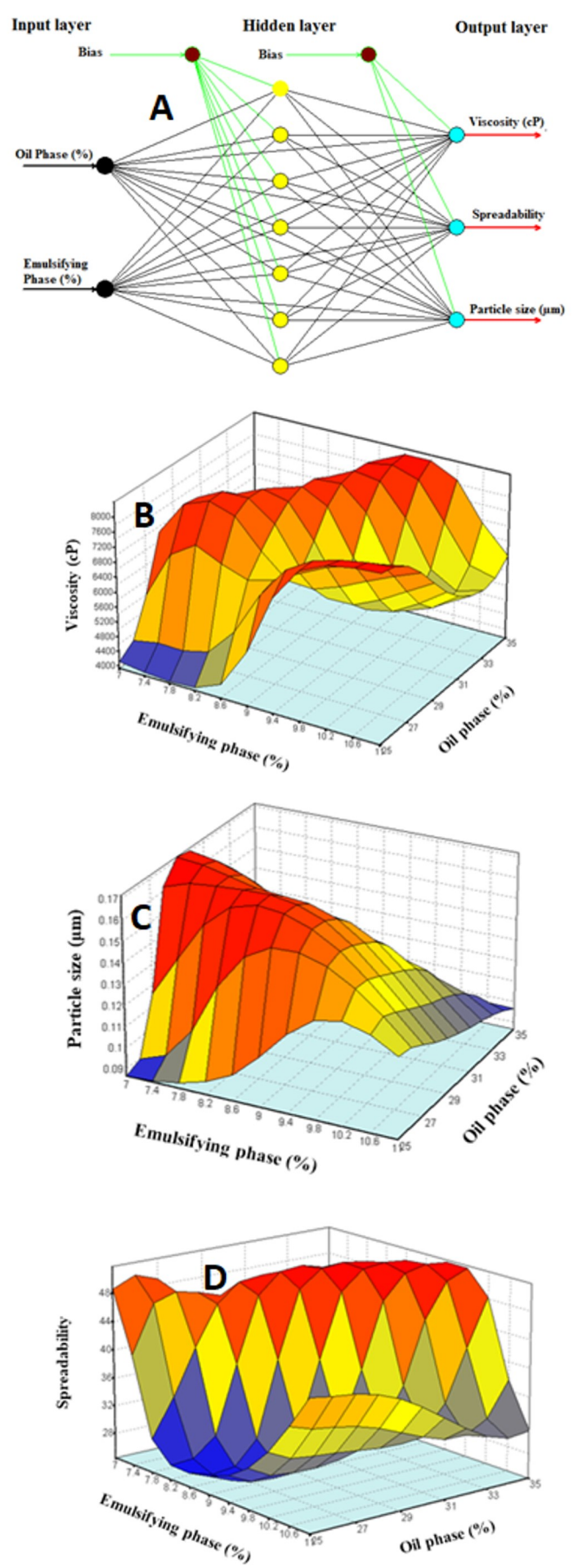

Figure 3. Architecture of the optimal ANN for predicting viscosity, Spreadability and Particle Size (A); response surface plot showing the effect of oil phase and emulsifying phase on viscosity (B); response surface plot showing effect of oil phase and emulsifying phase on particle size $(C)$; response plot showing effect of oil phase and emulsifying phase on spreadability (D).

Similarly, spreadability also decreased with an increase in the oil phase level, although its effect was not significant compared to the emulsifying phase. Particle size increased with an increase in the emulsifying phase level, as seen from Figure 3C. On the other hand, the utilization of intermediate oil phase levels resulted in high particle size values.

\section{DISCUSSION}

Despite the multitude of alternatives available at present, the interest in natural product cosmeceuticals is increasing. The medicinal plants present great potential in developing such new products considering different beneficial properties 
such as antioxidant effects, stimulation of collagen synthesis, improvement of the skin elastic properties, photoprotection, and moisturizing. Besides, natural ingredients are well tolerated, and the incidence of side effects to herbal extracts is extremely rare [11,12]. They are usually derived from extensive research and, since there are of mostly natural origin, do not have associated side effects synthetic products have, such as irritancy and carcinogenicity. The Draize test carried out showed the cream formulations had no sensitizing effects like erythema and oedema.

The free radical scavenging property of the cream was analyzed. In Figure $\mathbf{2 A}$, the absorbance of the extract decreased as the concentration of the extract increased. This could be attributed to the effect of the antioxidants present in the extracts (lemongrass, basil, and roselle aqueous extracts). These antioxidants reacted with the free radicals of DPPH; they thus depleted the amount of the DPPH radicals present in the reaction mixture as shown in Figure 2B, which illustrates the percentage inhibition of the extracts as concentration increased. However, the antioxidant potential of the extracts, as seen from Figure 2B, is not as high as that of the reference used (Ascorbic acid). Still, it showed marked free radical scavenging properties.

Cetyl palmitate and cetostearyl alcohol were chosen for their thickening properties as well as inherent emulsifying ability. The percent used (1\%) was arrived at after trial and error using initially higher concentrations in formulating sample batches. Initial products formed at higher concentrations of Cetylpalmitate and Cetostearyl alcohol were too viscous and presented difficulty in emulsification with the hand blender used for this work. The plant extracts used all have been shown to have various degrees of antioxidant, anti-aging, and antimicrobial properties [3-4,1214]. However, in these studies, the cold water extracts of the plants were found to have moderate to low antimicrobial properties. The finding of this work agreed with their findings. The concentration of the crude extracts used is low $0.25 \%$, and as such, their antimicrobial properties will be at a minimum. This necessitated the use of preservatives.

The emulsifiers (span 60 and tween 80) chosen for the work have also been shown to form stable cream formulations that are non-irritant and non-toxic at use concentrations used for the work [13]. During the emulsification of the cream, some other factors which were not taken into consideration in this study might have had some undetermined influence on the properties of the cream formulation of interest (particle size, spreadability, and viscosity). Such factors include the duration of emulsification, the temperature at which the oil and aqueous phases were mixed before emulsification, the distance the homogenizer was immersed into the formulation during emulsification, and the speed of the blending equipment rotor blades. However, to reduce the influence of these factors, these attributes were kept as much as possible constant, and each cream formulation was prepared in triplicate to reduce error due to unforeseen variability.

The central composite design methodology was found not to provide a good prediction of an optimized product using experimentation data. Thus, artificial neural networks software was used to design an optimization model and predict an optimized product and also to generate response surface plots showing the relationship between the various independent variables and the dependent variables. The optimization predictions were confirmed by preparing in triplicate cream formulations using the recommended values of the independent variables. The average responses from the trials obtained were found to be comparable with predicted optimization results. This thereby confirms that the formulation has been optimized. The optimized formulation was also found to possess a low creaming index, no variation in $\mathrm{pH}$ on standing, and other physicochemical properties on storage.

The response surface plots show the relationship between the responses (viscosity, spreadability, and particle size) and the input factors (oil phase and emulsifying phase). Viscosity was found to increase with an increase in the level of the emulsifying phase. This could be attributed to the availability of the emulsifier to form a micellar layer around the oil globules and thus stabilize the formed emulsion. A minimum amount of surfactant is needed to cover the smallest possible droplets, protecting them against coalescence and Ostwald ripening. But, as already noticed by Nikovska et al. [15], there is an optimum value of emulsifier required for emulsion stability. This optimum value is attributed to the competing role of repulsive structural versus attractive depletion forces. At low micellar concentrations, the depletion interactions between droplets result in lower stability, while at higher micellar concentrations, the structural forces induce a repulsive energy barrier, which enhances stability. This is evident from the study as for the increase in emulsifier concentration.

The reverse was observed concerning the oil phase level as the viscosity was observed to decrease when the oil phase was increased. The increased oil phase and reduced emulsifier concentration amounted to reduced emulsification on agitation. The creaming behavior correlates with the reports from Nikovska et al. [15], where the emulsions with higher viscosity show better emulsion stability against creaming. Therefore, at low oil concentration, the viscosity of the emulsion is low, droplet aggregation and floc formation are enhanced, and creaming is rapid since the weakly flocculated network simply collapses under its own weight [16]. On the contrary, in the emulsions containing higher oil phase concentrations, droplets are more densely packed, which increases emulsion viscosity, enhances the inter droplet interactions and network formation, and thus lowers the creaming rate [14].

Spreadability decreased with an increase in the emulsifying phase. Similarly, spreadability also decreased with an increase in the oil phase level, although its effect was not significant compared to the emulsifying phase. The above factors have already been shown to cause an increase in viscosity of the cream formulation. Thus, it can be said that as the viscosity of the preparation increased, the spreadability of the formulation decreased. This agreed with the findings of Inoue et al. [17], which showed that differences in the oil and water content of cream formulations affected the physicochemical properties of a cream, such as skin penetrability, viscoelasticity, flattening, and internal structure. 
Particle size increased with an increase in the level of the emulsifying phase, as seen. On the other hand, intermediate levels of the oil phase resulted in high values of particle size. This agreed with Nikovska et al. [15] in establishing that droplet/particle aggregation was dependent on surfactant availability. However, this was up to an optimum value, which was predicted using anterior neural networks to be at optimum values of $0.12 \mu \mathrm{m}$. Other factors, such as homogenizer emulsification speed, temperature, polymersurfactant interactions, and duration of emulsification, have been identified in the literature to affect the particle size of the final product [18]. Polydispersity/droplet size distribution also like viscosity, has also been shown to be related to the stability of the cream. As the oil phase increased, the particle size of droplets was found to increase. This is due to the increased coalescence which occurred in the formulation. Thus, the droplets formed were bigger. Temperature, duration of emulsification, and emulsification speed could be other factors that could influence the particle size.

The predicted values for the optimized cream formulation considered the various factors already discussed above (viscosity, spreadability, and particle size). The predicted values did not differ significantly from the experimentally obtained values. The formulated cream was of moderate viscosity and on examination for creaming showed no creaming after seven days. Some creaming was observed after 15 days. The value of the emulsifier predicted from optimization is $11 \%$, which is the maximum percentage of the emulsifier used in the experimental design. However, there is a possibility that increasing the amount of the emulsifier will lead to products of superior stability profile, viscosity, and spreadability.

\section{CONCLUSION}

Formulation of the polyherbal face cream containing Cymbopogon citratus, Hibiscus sabdariffa, and Ocimum gratissimum extracts were prepared and were shown to have significant antioxidant activity. Central Composite Design was used to prepare a framework for the formulation design. This framework was then used to prepare various cream formulations using palm oil as the oil base and Tween 80/ Span 60 as the emulsifying phase. Using advanced neural network modeling, a prediction of an optimized formulation was made. The optimized values for oil and emulsifying phase were found to be $27.86 \%$ and $11 \%$, respectively. The predicted responses were found to be: spreadability indices, $47.01 \%$, particle size, $0.12 \mu \mathrm{m}$, and viscosity of $8355.85 \mathrm{cp}$. The optimized formulation was prepared and was shown to have comparable results with the predicted values.

\section{ACKNOWLEDGMENTS}

None.

\section{CONFLICT OF INTEREST DECLARATION}

The authors report no conflict of interest. The authors alone are responsible for the content and the writing of the paper.

\section{FINANCIAL SUPPORT}

This research received no grant from any funding agency/ sector.

\section{AUTHOR IDs}

MOI: Margaret O. Ilomuanya

ORCID: 0000-0001-8819-1937

CPO: Chukwuebuka P. Onwubuya

ORCID: -

ANA: Andrew N. Amenaghawon

ORCID: 0000-0003-0433-0114

\section{AUTHOR CONTRIBUTIONS}

Concept: MOI; Design: MOI, ANA; Supervision: MOI, CPO, ANA; Materials: MOI, CPO; Data Collection and/or Processing: ANA, CPO; Analysis and/or Interpretation: MOI, CPO, ANA; Literature Search: MOI, CPO; Writing: MOI, CPO, ANA; Critical Reviews: MOI, CPO, ANA.

\section{REFERENCES}

[1] Ilomuanya MO, Amenaghawon NA, Odimegwu J, Okubanjo OO, Aghaizu C, Oluwatobiloba A. Formulation and optimization of gentamicin hydrogel infused with tetracarpidium conophorum extract via central composite design for topical delivery. Turk J Pharm Sci. (2018); 15(3): 319-327. https://doi.org/10.4274/tjps.33042

[2] Edeoga HO, Omosun G, Uche LC. Chemical composition of hyptissuaveolens and ocimum gratissimum hybrids from Nigeria. Afr J Biotechnol. (2006); 5(10): 892-895.

[3] Akinmoladun EO, Ibukun AE, Obuotor EM, Farombi EO. Phytochemical constituent and antioxidant activity of extract from the leaves of ocimum gratissimum. Sci Res Essays. (2007); 2(5): 163-166.

[4] Chiu YW, Lo HJ, Huang HY, Chao PY, Hwang JM, Huang PY, Lai TJ. The antioxidant and cytoprotective activity of, ocimum gratissimum extracts against hydrogen peroxide-induced toxicity in human HepG2 cells. J Food Drug Anal. (2013); 21(3): 253-260. https://doi.org/10.1016/j.jfda.2013.07.002

[5] Ademiluyi AO, Oboh G. Aqueous extracts of roselle (hibiscus sabdariffa Linn.) varieties inhibit $\alpha$-amylase and $\alpha$-glucosidase activities in vitro. $J$ Med Food. (2013); 16(1): 88-93.

https://doi.org/10.1089/jmf.2012.0004

[6] Carmo ES, Pereira F, Cavalcante NM, Gayoso CW, Lima E. Treatment of pityriasis versicolor with topical application of essential oil of cymbopogon citratus (DC) stapf - therapeutic pilot study. $A n$ Bras Dermatol. (2013); 88(3): 381-385. https://doi.org/10.1590/abd1806-4841.20131800

[7] Amenaghawon NA, Amagbewan E. Evaluating the effect of acid mixtures and solids loading on furfural production from sugarcane bagasse: Optimization using response surface methodology and artificial neural network. RJEES. (2017); 2(2): 578-587.

[8] Nath A, Chattopadhyay PK. Optimization of oven toasting for improving crispness and other quality attributes of ready to eat potatosoy snack using response surface methodology. J Food Eng. (2007); 80(4): 1282-1292.

https://doi.org/10.1016/j.jfoodeng.2006.09.023

[9] Fahimi S, Mortazavi SA, Abdollahi M, Hajimehdipoor $\mathrm{H}$. Formulation of a traditionally used polyherbal product for burn healing and HPTLC fingerprinting of its phenolic contents. Iran $J$ Pharm Res. (2016); 15(1): 95-105.

[10] DjiobieTchienou G, TsatsopTsague R, MbamPega T, Bama V, Bamseck A, DongmoSokeng S, Ngassoum M. Multi-response optimization in the formulation of a topical cream from natural ingredients. Cosmetics. (2018); 5(7): 1-14. https://doi.org/10.3390/cosmetics5010007

[11] Shen Q, Zhang B, Xu R, Wang Y, Ding X, Li P. Antioxidant activity in vitro of the selenium-contained protein from the Se-enriched Bifidobacterium animalis 01. Anaerobe. (2010); 16 (4): 380-386. https://doi.org/10.1016/j.anaerobe.2010.06.006

[12] Ilomuanya MO, Okubanjo OO, Azubuike CP, Oguntibeju A. Evaluation of the frequency of use of herbal drugs with concomitant administration of highly active antiretroviral therapy and its effect on medication adherence in two health care facilities in south western Nigeria. J AIDS HIV Res. (2017); 9(1): 8-16.

https://doi.org/10.5897/JAHR2016.0399

[13] Ilomuanya MO, Akhimien T, Aghaizu C, Adeyinka O, Ajayi T. Polyherbal antioxidant topical preparation comprising ethanol extract of tetracarpidium conophorum and ocimum gratissimum: Formulation and evaluation. Dhaka Univ J Pharm Sci. (2018); 17(2): 213-219. https://doi.org/10.3329/dujps.v17i2.39178 
[14] Moldovan M, Lahmar A, Bogdan C, Părăuan S. Formulation and evaluation of a water-in-oil cream containing herbal active ingredients and ferulic acid. Clujul Med. (2017); 90(2): 212-219. https://doi.org/10.15386/cjmed-668

[15] Nikovska K. Study of olive oil-in-water emulsions with protein emulsifiers. Emir J Food Agric. (2012); 24: 17-24. https://doi.org/10.9755/ejfa.v24i1.10594

[16] Sun C, Gunasekaran S. Effects of protein concentration and oil-phase volume fraction on the stability and rheology of menhaden oil-inwater emulsions stabilized by whey protein isolate with xanthan gum. Food Hydrocoll. (2009); 23(1): 165-174.

https://doi.org/10.1016/j.foodhyd.2007.12.006
[17] Inoue Y, Suzuki K, Maeda R, Shimura A, Murata I, Kanamoto I. Evaluation of formulation properties and skin penetration in the same additive-containing formulation. Res Pharm Sci. (2014); 4: 42-49. https://doi.org/10.1016/j.rinphs.2014.09.003

[18] Dapčević-Hadnađev T, Dokić P, Krstonošić V, Hadnađev M. Influence of oil phase concentration on droplet size distribution and stability of oil-in-water emulsions. Eur J Lipid Sci Technol. (2013); 115(3): 313-321.

https://doi.org/10.1002/ejlt.201100321 